Pasado y Memoria

ISSN: 2386-4745

Núm. 23, 2021, pp. 236-259

https://doi.org/10.14198/PASADO2021.23.10

Estudios

\title{
La cara oculta de la contrainsurgencia franquista a través de un mando de la Guardia Civil: la experiencia de Eulogio Limia Pérez
}

\section{The hidden side of Franco's counterinsurgency through a Civil Guard officer: Eulogio Limia Pérez's experience}

\author{
Arnau Fernández Pasalodos \\ Universitat Autònoma de Barcelona, España \\ arnaupasalodos@gmail.com \\ https://orcid.org/0000-0002-2927-3008
}

Recibido: 19/01/2021

Aceptado: 17/05/2021

Cómo citar este artículo: FERNÁNDEZ PASALODOS, Arnau (2021). La cara oculta de la contrainsurgencia franquista a través de un mando de la Guardia Civil: la experiencia de Eulogio Limia Pérez. Pasado y Memoria. Revista de Historia Contemporánea, (23), pp. 236-259, https://doi.org/1014198/PASADO2021.23.10

\section{Resumen}

El análisis de las estrategias contrainsurgentes desarrolladas por el bando sublevado y por la dictadura franquista se ha visto relegado a un segundo plano en la historiografía. Las publicaciones cuyo objeto de estudio han sido el surgimiento, el progreso y el ocaso de las agrupaciones, o partidas guerrilleras, han eclipsado de forma habitual la investigación relativa a las experiencias de los agentes represores. El objetivo del presente estudio es mostrar cómo las estrategias antiguerrilleras favorecieron el proceso de radicalización experimentado en el seno de la Guardia Civil, al mismo tiempo que generaron contradicciones, miedos y tensiones internas dentro del Instituto. Para ello, se recurre a documentación del teniente coronel Eulogio Limia Pérez y a bibliografía especializada sobre la guerrilla antifranquista.

Palabras clave: Lucha antiguerrillera; Guerra Civil Española; Guardia Civil; Guerrilla antifranquista. 


\begin{abstract}
The study of the counter-insurgent strategies developed by the rebels and by Franco's dictatorship has been rather neglected. Previous research devoted to the analysis of the emergence, the progress -and end of the guerrillas have usually overshadowed the role of repressor agents. The aim of this paper is to show the extent to which the anti-guerrilla strategies favoured the radicalization process of the Civil Guard members, while promoting contradictory positions, fear and internal tension among them. For this purpose, we draw both on Lieutenant Colonel Eulogio Lmia Pérez's papers and anti-francoist guerrilla spacialised bibliography.
\end{abstract}

Keywords: Anti-guerrillas Fighting; Spanish Civil War; Civil Guard; Antifrancoist Guerrilla.

Financiación: La realización de este artículo se enmarca en el proyecto de $\mathrm{I}+\mathrm{D}+\mathrm{i}$ del Ministerio de Ciencia, Innovación y Universidades «Posguerras civiles: violencia y (re) construcción nacional en España y Europa, 1939-1949» (PGC2018-097724-BI00).

Agradecimientos: Quiero dar las gracias a los/as evaluadores/as anónimos/as de este trabajo por sus consejos y críticas, que han ayudado a mejorar el contenido final. Y, muy especialmente, agradecerle a Javier Rodrigo su apoyo en este proceso predoctoral. La presente investigación y otras tantas que están por llegar no serían posibles sin sus consejos y su amistad.

\title{
Introducción. La Guardia Civil y sus especialistas en la guerra irregular
}

La lucha antiguerrillera desplegada por el bando sublevado y a posteriori por el Nuevo Estado entre 1936 y 1952 hizo que toda una serie de cuadros y mandos en la Guardia Civil se especializaran en labores de contrainsurgencia. Hombres como Pascual Arbona Puig, Fernández Montes de Oca, Luis Marzal Albarrán, José Blanco Novo, Bruno Ibáñez Gálvez, Santiago Garrigós Bernabéu, Arturo Puga Noguerol o Francisco Aznar Iriarte escribieron a través de sus órdenes y de sus acciones algunas de las páginas más oscuras de la historia de la Benemérita. Todos ellos se labraron trayectorias controvertidas a consecuencia de los métodos brutales y de guerra sucia que emplearon contra los guerrilleros, los enlaces y la población civil que vivía en el teatro de operaciones. No obstante, han sido dos las biografías que han aparecido con mayor frecuencia en la historiografía, la del teniente coronel Manuel Gómez Cantos y la del general Manuel Pizarro Cenjor (García Carrero, 2013, 2014; Abad Gallego, 2004; Yusta, 2005; Sánchez Cervelló, 2006).

Todos estos hombres estuvieron bajo el mandato directo y la estrecha supervisión de Franco y de Camilo Alonso Vega. Los dos ferrolanos habían 
forjado una notable amistad con el paso de los años al compartir pupitres en la academia militar, pero sobre todo durante su etapa en Marruecos. Cuando Franco pasó a ser el director de la Academia General de Zaragoza en 1928 no se olvidó de su buen amigo Camilo, al que nombró profesor. Tampoco lo hizo en 1943, cuando lo situó al frente de la Guardia Civil (Blanco Escolá, 2000, p. 160). El contexto internacional cada vez más desfavorable para el régimen, así como el auge de la resistencia armada contra la dictadura, hicieron que Franco eligiese a un hombre de su máxima confianza para comandar la institución que debía llevar el peso de la lucha antiguerrillera. El propio Alonso Vega se basó en criterios de afinidad y confianza personal para nombrar a los mandos al frente de las provincias más afectadas por la guerrilla republicana, como el teniente coronel Eulogio Limia Pérez, que se convirtió en uno de los mayores expertos del régimen en contrainsurgencia.

\section{La trayectoria de Eulogio Limia Pérez}

Tal fue el grado de conocimientos y de éxito que alcanzó Limia Pérez que el director general recurrió a él enviándolo a aquellos destinos donde la resistencia había logrado doblegar a otros mandos del Instituto Armado. Por ejemplo, ante el auge de la guerrilla en Toledo fue designado como jefe de la 104 Comandancia, acabando con ella en solo dos años. Esta victoria le hizo recalar en la 204 Comandancia de Ciudad Real, donde también resolvió el problema de la resistencia armada en tan solo un par de años. A finales de los años cuarenta la guerrilla antifranquista se encontraba en franca decadencia, la feroz represión ejercida por la dictadura y el abandono de las democracias europeas y de la Unión Soviética fueron las causas principales. Buena parte de las agrupaciones y partidas habían desaparecido o se encontraban por entonces en fase de liquidación. No obstante, algunas aguantaban todavía los embates represivos, como la guerrilla granadina, de ahí que en aquella última etapa Franco y Alonso Vega volvieron a confiar en Limia Pérez. Por orden ministerial fue designado jefe de la 136 Comandancia de Granada en octubre de 1949, gozando de un mando único para comandar a la tropa del Cuerpo (Marco, 2013, p. 16; Díaz, 2004, pp. 106-107).

Las estrategias antiguerrillas y los resultados exitosos de su paso por la provincia andaluza, así como por el resto de las comandancias, han sido cuestiones convenientemente analizadas en la historiografía, especialmente por Jorge Marco (2013). El presente artículo tratará de complementar dicho trabajo, mostrando cómo la propia experiencia de Limia Pérez y sus métodos contrainsurgentes contribuyeron a la radicalización de la guerra contrainsurgente, al mismo tiempo que provocaron contradicciones y tensiones internas 
dentro del cuerpo. En definitiva, el objetivo será tratar estos temas, que son todavía hoy la cara oculta de la contrainsurgencia franquista.

Además, utilizar la trayectoria de este mando de la Guardia Civil como pretexto para trabajar dichos aspectos tampoco es casual, ya que hablar de Eulogio Limia Pérez es hacerlo a su vez de la guerra irregular, siendo ambos absolutamente inseparables. Limia fue uno de los guardias civiles que se especializó desde el principio de la lucha contra una guerrilla que surgió en el verano de 1936 como forma de resistencia armada frente a la violencia y las llamadas a filas en algunas de las regiones donde los golpistas lograron controlar el territorio. Galicia fue tierra de fuxidos desde los primeros compases de la guerra y este oficial de la Benemérita se convirtió en uno de los encargados de perseguirlos y exterminarlos en dicha región.

Efectivamente, en 1937 Limia Pérez tenía la graduación de capitán y estaba destinado en la comandancia de Ourense. Sus superiores confiaron en su capacidad de mando y le confirieron el control de los grupos de guardias, soldados y falangistas que se estaban encargando de perseguir a las partidas guerrilleras en las zonas limítrofes de la provincia gallega y León. Tal era la envergadura del problema que en junio de 1937 el gobernador militar de Ourense ordenó el regreso de todos los guardias civiles que habían marchado hacia Asturias para colaborar con el Ejército sublevado en el Frente Norte. Centenares de efectivos volvieron a tierras gallegas, encontrándose allí con el capitán Limia Pérez, quien recibió del gobernador militar la orden de dirigir todas las operaciones antiguerrilleras. ${ }^{1}$ Desde entonces el capitán no dejaría de ascender en el escalafón militar, a la par que obtenía nuevos destinos en diferentes puntos de la península durante los años cuarenta y cincuenta, siempre con el cometido de sofocar la resistencia armada republicana. Allí donde otros oficiales o suboficiales fallaban Franco y Camilo Alonso Vega confiaron en él para revertir la situación, demostrándoles que no estaban equivocados. Con plenos poderes, plantillas extensas y dotaciones económicas de envergadura Limia Pérez logró desempeñarse con éxito allí donde estuvo destinado. Él mismo fue el encargado de organizar todos los operativos para dar con los dos últimos guerrilleros republicanos, los célebres Juanín y Bedoya. A tal fin destinó centenares de guardias a tierras cántabras, quedando bajo sus órdenes, y aunque le costó dar con ellos ambos fueron abatidos en 1957.

De esta forma, Eulogio Limia Pérez estuvo destinado a la lucha antiguerrillera durante 20 años, desde los primeros días del verano del 36 hasta el fin de los dos últimos guerrilleros republicanos. Ningún otro mando de la Benemérita

1. Archivo General Militar de Ávila, en adelante AGMAV. Caja 1476, carpeta 23. 
estuvo encargado de labores contrainsurgentes durante tanto tiempo. Con todo ello, Limia se acabó convirtiendo en la encarnación del éxito de la contrainsurgencia sublevada y franquista, pero la forma en que desempeñó sus labores también nos pone ante otros aspectos a menudo olvidados de la guerra irregular que están en el centro de este artículo: las tensiones internas y las contradicciones dentro de la Guardia Civil, que hicieron que las broncas, la intransigencia, el miedo y el fracaso fueran parte del día a día de la tropa, de los suboficiales y oficiales del cuerpo.

\section{Algo más que bandolerismo: Limia y las contradicciones del discurso oficial del régimen}

La dictadura franquista trató de silenciar la existencia de una auténtica guerra que se extendió más allá del primero de abril de 1939, pero que a su vez venía de lejos. Los esfuerzos por censurar la información de la lucha contra la guerrilla funcionaron, imponiéndose las décadas de silencio y la construcción de una narrativa franquista que presentó siempre a los guerrilleros como bandoleros. De este modo no es extraño que todavía hoy encontremos investigadores que siguen tildando a los resistentes antifranquistas de bandoleros (Chamorro Rodríguez, 2019). No obstante, una cosa es la propaganda y otra muy distinta la realidad. A pesar de que los encargados de la represión estuvieron obligados a no emplear términos como «maquis» o «guerrilleros», su experiencia de guerra y el hecho de saber que sus oponentes no eran simples delincuentes terminaron por imponerse frente a las versiones construidas desde la cúspide. De esta forma, fue habitual que los guardias civiles se vieran traicionados por su propio subconsciente y que en los informes y comunicaciones utilizasen continuamente los términos prohibidos, ${ }^{2}$ o directamente decidieron escribir sobre la lucha irregular sin seguir al detalle todas aquellas imposiciones.

De esta forma, el propio Limia Pérez no tuvo reparos en señalar que entre 1939 y 1952 existió una guerra abierta entre la dictadura y la guerrilla:

«No se puede olvidar, que el tesón, energía, ánimo esforzado, constancia y espíritu de sacrificio, que requiere el servicio de bandolerismo, es a mi modesto juicio superior al de otra campaña regular cualquiera, por tratarse pudiéramos decir, de una guerra fría, callada y silenciosa en donde apenas se ve al enemigo y el mantenimiento constante de una moral elevada, se hace

2. Tal fue el grado de incumplimiento de la orden de no utilizar términos como «maquis» o «guerrilleros» que la Dirección General de Seguridad tuvo que emitir la misma orden en sucesivos años. Véase Archivo Histórico Provincial de Sevilla, en adelante AHPSev. GC1, Registro 32, fichero 345 y 346; AHPSev. GC1, Registro 34, fichero 143; y Archivo Histórico Provincial de Castellón, en adelante AHPCast. Gobierno Civil, caja 11262. 
muy difícil, porque no se encuentran los estímulos que producen las victorias, ni los que mutuamente se transmiten en una guerra, las distintas fuerzas combatientes y el pueblo y la prensa en masa, exaltada por un elevado fervor patriótico, máxime si se añade que en nuestro problema de bandolerismo, por las especiales circunstancias políticas e internacionales de aquellos años, fué [sic] preciso rodear de silencio, no solo las destacadas actuaciones y éxitos de las fuerzas del Cuerpo, sino asimismo el volumen y gravedad de la acción de las partidas, solamente conocidos unos y otros, por el elemento civil de la comarca donde se desarrollaban, sin tener noticia de lo que ocurría en zonas alejadas en la misma provincia y mucho menos de las circunstancias por las que atravesaban las demás». ${ }^{3}$

El oficial siguió empleando el término «bandoleros», pero se negaba a ocultar la realidad. Vale decir que no entendía que se tratara de un conflicto armado cuyo inicio o factor tuviera que ver con el rechazo del régimen a reintegrar a los vencidos en la sociedad de postguerra. Por el contrario, Limia Pérez defendía que tras el fin del conflicto regular habían quedado en buena parte de las provincias algunos grupos de hombres que «habiendo participado en la lucha en el bando rojo, o encontrándose ocultos o huidos en los montes, trataban de eludir las responsabilidades de la guerra, de sus fechorías y actos criminales durante el dominio marxista o de los primeros tiempos del Alzamiento». ${ }^{4}$ De esta forma, el guardia se ceñía parcialmente a la narrativa impuesta por el régimen, según la cual los huidos y las primeras partidas guerrilleras quedaron perfilados como meros delincuentes comunes, negando así cualquier motivación política a su acción. De hecho, el discurso oficial mantuvo siempre que el principal móvil de los resistentes armados fue el afán por lucrarse económicamente, a la par que huir de la justicia por supuestos actos criminales cometidos entre 1936 y 1939. Por tanto, el insurgente ejercía el bandolerismo como forma de subsistencia, obviándose que la mayor parte de estas personas se refugiaron en los montes a causa del terror generado por la Guardia Civil, las columnas falangistas y las delaciones de aquellos vecinos que deseaban beneficiarse dentro del Nuevo Orden.

Siempre que pudo, Limia Pérez trató de dignificar y ensalzar el papel de la Benemérita a la vez que reforzar esa despolitización de la guerrilla republicana. Al mismo tiempo escribió que la fuerza del cuerpo mantuvo una enconada lucha contra las partidas, sin darles tregua ni de día ni de noche, logrando acabar con algunas mientras que diezmaban efectivos de otras. Un combate en

3. Archivo del Partido Comunista de España, en adelante AHPCE. Movimiento guerrillero, Reseña del problema del bandolerismo en España, Caja 105, carpeta 3/2.

4. AHPCE. Movimiento guerrillero, Reseña del problema del bandolerismo en España, Caja 105 , carpeta $3 / 2$. 
el cual los «malhechores» no contaron «en general con la colaboración y ayuda de la población civil tan necesaria en el campo, produciendo por el contrario repugnancia sus crímenes y actos de pillaje». En esta ocasión, hallamos una nueva manipulación o contradicción en su discurso, pues resulta completamente falso y el único objetivo aquí es reforzar la visión criminal de la acción de los huidos. Tal y como han venido demostrando las investigaciones en las últimas décadas, si hubo un elemento central que permitió a huidos y guerrilleros sobrevivir durante más de una década fue precisamente la colaboración civil (González Devís, 2016 y 2018; Marco, 2012; Yusta, 2003 y 2005). Ello fue lo que hizo que la represión para eliminar a las partidas de huidos y guerrilleros se centrara especialmente en la población local. Por lo que este análisis de Limia Pérez, que iba en perfecta consonancia con la narrativa franquista, acabó siendo refutado por las propias órdenes y comunicaciones de la Guardia Civil, que establecieron en el centro de las prácticas contrainsurgentes a los familiares, amigos y a la población que vivía en el teatro de operaciones.

No obstante, lo más interesante de analizar la documentación de Limia Pérez es precisamente comprobar esas continuas contradicciones en sus análisis, una tónica habitual en todos los mandos de la Guardia Civil. Para ello acudo nuevamente a una fuente citadísima en la historiografía, como su reseña sobre «el problema del bandolerismo» de 1957. En ella terminó reconociendo la existencia de una primera fase de huidos y de una segunda fase de actuación de «guerrilla comunista». Si en el párrafo anterior hemos comprobado cómo trató de despolitizarla totalmente, ahora aseguraba que el PCE comenzó a organizar «la lucha subversiva contra el Régimen, utilizando los restos de las pequeñas partidas de huidos y bandoleros, que quedaban en el campo, encuadrándolos en unidades de tipo militar sometidas a disciplina». Unos grupos que terminaron por formar agrupaciones y unidades guerrilleras que tenían como objetivo «formar en su día los cuadros de las grandes unidades, cuando la agitación y adhesión de las masas populares, hubiese alcanzado el volumen deseado». Por tanto, vemos cómo Limia rehuía en su análisis una total deformación de la guerrilla, pues en su condición de destacado represor de la resistencia no podía obviar que los guerrilleros republicanos habían contado con un «mando militar auxiliado por un titulado Estado Mayor y un mando político», y que se dividían en «Divisiones, Brigadas, Batallones y Zonas». Por tanto, asumía que se habían estado enfrentando a una organización que se estructuraba como un Ejército y que empleaba «la guerra de guerrillas y sabotajes, pero no en sentido ofensivo sino por el contrario rehuyendo los encuentros con la fuerza de persecución [...] manteniendo solamente una actitud militar vigorosa y enérgica, cuando eran atacados». 
La «reseña del problema de bandolerismo» por parte del teniente coronel acabó desmontando por si misma cualquier posibilidad de tildar de bandolerismo la acción guerrillera antifranquista. El propio guardia civil llegó a explicar en su análisis que los guerrilleros tras dar golpes económicos dedicaban buena parte de los beneficios a abonar «el importe de sus comidas y artículos de que se suministraban, los cuales eran adquiridos por confidentes o enlaces de confianza». Por no olvidar la importante labor propagandística que realizaron y que Limia no dudó en señalar como una acción política, ya que las hojas de propaganda que lanzaban siguieron las consignas del PCE, así como «los ideales que perseguía la actuación guerrillera», que pasaban por «adoptar una actitud de resistencia hacia el Gobierno y Autoridades de la Nación».

Ahora bien, uno de los mejores ejemplos de la «rebeldía» de Limia Pérez en relación con la narrativa franquista lo encontramos en su informe general sobre la lucha antiguerrillera en Granada entre 1939 y 1952. En este documento estableció una clara diferencia entre el bandolerismo decimonónico y el de la década de los cuarenta, que de paso anulaba por completo las tesis oficiales del régimen:

«El tipo de bandolerismo que ha venido padeciendo España ha tenido en su totalidad una ideología e inspiración netamente política de sentido comunista [...] diferente del antiguo bandolerismo de la época de las Hermandades y primeros tiempos de la Guardia Civil en el siglo pasado que tenia [sic] un matiz puramente personal y de pillaje».5

Limia Pérez no estaba afirmando nada novedoso, pues no era el primer mando del cuerpo que no dudaba en reconocer la dimensión política de las guerrillas. Por ejemplo, el jefe de la Comandancia de Málaga reconocía en un escrito de enero de 1948 que una parte importante de los asesinatos que cometían los guerrilleros no tenían que ver únicamente con los supuestos «instintos criminales» asociados a ese bandidaje, tal y como pretendió mostrar el régimen, sino que ejecutaban a personas por «venganza política». ${ }^{6}$ No obstante, debemos tener en consideración que estos guardias civiles y otros hagiógrafos de la dictadura no hicieron otra cosa que seguir la tendencia que el bloque capitalista estaba marcando en el marco de la Guerra Fría: despolitizar al comunismo mediante su criminalización. Así, mientras algunos autores establecieron que los guerrilleros eran unos criminales patológicos sin ningún tipo de motivación u objetivo político, otros como Limia Pérez reforzaron su acción como la de un

5. AHPCE. Movimiento guerrillero, Documentos Guardia Civil. 136. Comandancia de Granada. Informes. Caja 106. Carpeta 1/5.

6. Archivo Histórico Provincial de Málaga, en adelante AHPMal. Gobierno Civil, caja 12633. Bandoleros, guerrilleros, contrabandistas. Años 1938-1953. 
«bandolerismo comunista» en la que el carácter criminal residía precisamente en la ideología y no en una cuestión patológica. Este último movimiento permitió a la dictadura hacer méritos en su intento por romper el aislamiento al que había estado sometida y aproximarse a los estados occidentales mediante el anticomunismo (Marco, 2011, pp. 83-84; Fuentes González, 2015), pero no por ello, dejaban de construir un relato impregnado de contradicciones.

Otro foco de incoherencias entre lo establecido por el Estado y la realidad en el teatro de operaciones se pone de manifiesto en el seno del falangismo. En este sentido, llama poderosamente la atención cómo en los informes de las distintas jefaturas provinciales de Falange se informaba a Madrid de las «actividades clandestinas de tipo político». Lejos de informarse solamente de células de resistencia comunista, anarquista o de cualquier otra ideología contraria a la dictadura, se comunicaban de los hechos más destacados relacionados con la guerrilla. Por citar un ejemplo, aunque encontramos decenas en distintas provincias, desde la Jefatura Provincial de Lugo escribían que se había liquidado un «brote de tipo comunista, tomando como base las guerrillas de atracadores que merodeaban por esta provincia desde hace algún tiempo». Desde la eliminación de esas partidas guerrilleras habían tenido lugar algunos hechos aislados en relación con más atracos "pero sin que a ellos, por las circunstancias en que se producen, pueda dárseles carácter político ${ }^{7}$ También desde la jefatura de A Coruña informaban en términos muy similares. Por ejemplo, en el parte mensual de octubre de 1946 el jefe provincial señalaba que tras unos meses de paralización habían vuelto a producirse actos violentos «por parte de elementos huidos y atracadores profesionales». Es decir, que los atracos los ejecutaban dos grupos: los guerrilleros por un lado y unos delincuentes comunes por el otro. ${ }^{8}$ Ahora bien, para sinceridad la del jefe provincial de Teruel, pues en mayo de 1947 no dudaba en señalar a la guerrilla como «el principal problema político que tenemos planteado» en la provincia. ${ }^{9}$

De esta forma, queda reflejado que en presencia de partidas guerrilleras los atracos revestían un carácter político, pero una vez eliminadas estas y efectuados otros atracos por delincuentes comunes esa dimensión desaparecía. En definitiva, no solo los guardias civiles como Limia contradecían parcialmente

7. Archivo General de la Administración, en adelante AGA. Presidencia, fondo 17.010. Caja 20674. «Parte mensual de actividades de abril de 1946».

8. AGA. Presidencia, fondo 17.010. Caja 20666. «Parte mensual de actividades de octubre de 1946».

9. AGA. Presidencia, fondo 17.010. Caja 20683. «Parte mensual de actividades de mayo de 1947». 
las tesis y discursos emanados del mismo Franco, sino también los propios falangistas.

\section{Conflictos internos en el seno de la Guardia Civil: entre el modus vivendi con la guerrilla y la radicalización de la lucha contrainsurgente}

La lucha antiguerrillera que desplegaron los sublevados desde el verano de 1936 vino aparejada de un proceso de radicalización característico de un contexto de guerra. Los métodos de «guerra sucia» como la aplicación masiva de la ley de fugas o las torturas en cuarteles fueron ordenados por Franco y los sucesivos directores de la Guardia Civil.

En esa espiral de sometimiento y violencia el teniente coronel Eulogio Limia Pérez jugó un papel destacadísimo. Sus reseñas sobre el «problema de bandolerismo» a nivel general o a través de su experiencia en comandancias como las de Ciudad Real o Granada son documentos muy conocidos. Por ejemplo, el historiador Jorge Marco (2006) señaló hace más de una década el potencial que esta serie documental tenía para el estudio de la guerrilla, ya que en los "papeles de Limia» podíamos encontrar resúmenes cronológicos de acciones guerrilleras, así como listas con los individuos que formaron las partidas y sus fechas de ingreso. En este sentido, Marco señalaba que los investigadores debíamos ser conscientes de que los saltos cualitativos en la historiografía se producen a través de la búsqueda de nuevos enfoques y modelos interpretativos. Pues bien, inspirado en este propósito, el presente epígrafe se sirve de una documentación muy citada para mostrar una realidad obviada hasta la fecha en las investigaciones. Si esas fuentes han sido convenientemente utilizadas y aprovechadas para elaborar biografías de guerrilleros o para tejer una cronología de las acciones de las distintas partidas, en las siguientes páginas comprobaremos que también nos permiten analizar la guerra irregular desde la propia experiencia contrainsurgente, precisamente la perspectiva de este artículo. El objetivo será comprobar la intransigencia y dureza que tuvo que soportar sobre sus espaldas la tropa del Instituto Armado en aquellas provincias que estuvieron afectadas por la presencia de partidas guerrilleras.

Tal y como señalaba anteriormente, los investigadores han centrado su atención en las listas de guerrilleros y en algunos hechos de armas de los que Limia dejó constancias en sus informes, por lo que sus arengas, las críticas y la intransigencia que mostró hacía otros mandos o la tropa han sido cuestiones que generalmente han quedado relegadas a un segundo plano. ${ }^{10}$ Por ejemplo,

10. En este sentido, hay que tener en cuenta que algunos autores sí han trabajado diferentes conflictos generados en el seno de la Benemérita. No obstante, sigue existiendo una 
en su análisis sobre Granada comentaba que entre 1947 y 1948 la guerrilla creció considerablemente en la provincia y culpó de ello tanto al buen hacer de su líder, el guerrillero «Roberto», como a la mala planificación y ejecución de la contrainsurgencia por parte de los responsables de la Guardia Civil:

«[...] por causas que no me es dable examinar, por tratarse de Jefes y Autoridades superiores, si bien se consiguieron distintos servicios aislados, por falta quizás de unidad en la actuación de todas las fuerzas, lo que impedía llevar la acción con un método único dirigido hacia objetivos concretos, se observó que el problema lejos de decrecer aumentaba de manera constante». ${ }^{11}$

Eulogio Limia se sintió siempre seguro dentro del Instituto por su impecable currículo, por contar con la confianza de Alonso Vega y por el destacadísimo papel que tuvo en todos los destinos por las que pasó como experto en la lucha contra la resistencia armada. Esto le hizo no temer a sus compañeros, consciente de que contaba con los apoyos adecuados, por lo que no dudó en criticar abiertamente incluso a alguno de sus superiores, un hecho a tener muy en cuenta en una institución tan jerarquizada como la Guardia Civil. Limia sabía como pocos mandos que la mejor baza en la guerra contrainsurgente era la obtención de información por encima del enfrentamiento directo con los partisanos, pero a pesar de ello también ordenó prácticas violentas con fines de exterminio.

El oficial indicaba que para llevar a cabo una estrategia basada en la información era necesario contar «con una fuerza preparada, entusiasta y decidida, con la cual por desgracia no se contaba en la mayor parte de las provincias». Además, se mostró muy crítico con las disputas internas dentro del Instituto a consecuencia de la forma en que se estaba gestionando la lucha antiguerrillera.

notable desproporción entre los estudios centrados en las tensiones generadas al calor de las partidas guerrilleras y de la Guardia Civil, siendo mayoritarios los relacionados con las primeras. Véase CHAVES PALACIOS, Julián (2001). Fuerzas del orden público y oposición al régimen de Franco en los cuarenta. Críticas de la Policía Armada a la Guardia Civil. En MORALES MOYA, Antonio (coord.), Las claves de la España del siglo XX. El Estado y los ciudadanos (221-233). Madrid: Sociedad Estatal España Nuevo Milenio; GARCÍA CARRERO, Francisco Javier (2013). Pereita Vela, Gómez Cantos y Navarrete Alcal, tres mandos de la Guardia Civil hermanados en la represión y en el deshonor en Badajoz durante la guerra civil y el primer franquismo. En CHAVES PALACIOS, Julián (dir.), El itinerario de la memoria. Derecho, historia y justicia en la recuperación de la memoria histórica en España, Vol. II (101-120). Madrid: Sequitur; y GARCİA CARRERO, Francisco Javier (2016). Navarrete Alcal, el guardia civil que «liberó» Fuente de Cantos del «yugo marxista». En LORENZANA DE LA PUENTE, Felipe (coord.), XVII Jornada de Historia de Fuente de Cantos (293-303). Badajoz: Sociedad Extremeña de Historia.

11. AHPCE. Documentos Guardia Civil. 136. Comandancia de Granada. Informes. Caja 106. Carpeta 1/3. 
Tras años combatiendo con éxito a la resistencia, en 1952 llegó a la conclusión de que una de las mejores tácticas para acabar con las partidas había sido la creación de sectores interprovinciales que permitían a un mismo jefe poder mandar a todas las fuerzas que debían acabar con los guerrilleros que se movían entre distintas provincias. Tal y como lo había hecho Manuel Pizarro Cenjor en la lucha contra la AGLA. No obstante, también señalaba que la puesta en práctica de esas fuerzas había fallado en algunas ocasiones por la falta de preparación de los mandos.

Por otra parte, señaló que su efectividad se había visto reducida a consecuencia de las disputas entre los jefes de comandancias, ya que algunos veían a los jefes de los sectores interprovinciales como adversarios que ponían en peligro tanto su mando como su posición dentro de la Guardia Civil. Cansado de las riñas y de los egoísmos de sus compañeros, así como de la falta de profesionalidad de alguno de ellos, no dudó en criticarlos de una forma tan sincera que vale la pena copiar literalmente el siguiente extracto de su informe:

«Esta unidad de Mando hubiera sido de gran eficacia y de mayores y más rapidos [sic] resultados en la lucha con este problema, si hubiera sido posible en la practica [sic] extenderla a la zona de varias provincias en las cuales actuaba una misma Agrupación de bandoleros, desligando el Jefe encargado, del mando de Comandancia y dedicándolo de lleno al servicio de bandolerismo, cuya idea fué [sic] ya prevista con certera visión por el Supremo Mando del Cuerpo, tanto por haberla organizado en varias zonas de la Peninsula [sic], como por la implantación en todas ellas de los Comandantes Jefes de Sectores Interprovinciales, si bien en la práctica no se obtuvieron los frutos que era de esperar, unas veces por falta de preparación y condiciones de los Jefes encargados y en lo que se refiere a los Comandantes de los Sectores, por las dificultades y trabas que en la mayor parte de los casos desconfianza de su lealtad, temiendo que cualquier éxito pudiera ser atribuido a las fuerzas de la provincia de su residencia, o en caso de fracaso, que tuviera éste resonancia en las mismas, pués [sic] es preciso confesar honradamente que por temperamento de la raza, por un excesivo amor propio y otras causas de menos entidad, no ha existido como era de desear entre los Jefes de las Comandancias limítrofes, el acuerdo, compenetración, y unidad de acción indispensables para batir las partidas que indistintamente actuaban en varias provincias». ${ }^{12}$

Completamente obsesionado por el éxito en la lucha antiguerrilla y por el cumplimiento de todas sus órdenes llegó a mandar en 1951, cuando era jefe de la Comandancia de Granada, que los oficiales y suboficiales llevasen a cabo un control exhaustivo de sus subalternos. Si de su paso por Ciudad

12. AHPCE. Documentos Guardia Civil. 136. Comandancia de Granada. Informes. Caja 106. Carpeta $1 / 5$. 
Real ha quedado constancia de las riñas constantes con los jefes y la tropa, en la documentación de su estancia en Granada se patentiza un proceso de aprendizaje en el que destacan dos aspectos. En primer lugar, la insistencia con la que exigía que cualquier orden fuese leída con asiduidad ante todos los guardias, $y$, en segundo término, la directriz de que los mandos ejerciesen un férreo control sobre la tropa:

«Los Jefes y Oficiales ejercerán la vigilancia del servicio consignado en mis órdenes especiales, observando desde los puntos dominantes, los lugares donde se encuentra la fuerza durante las horas de observación y presentándose en cualquier punto del itinerario durante los reconocimientos y correrías o en los cortijos tanto del itinerario como en los de pernocte, ilustrando a la fuerza en la elección de observatorios o apostaderos. Para esta vigilancia adoptarán las debidas precauciones principalmente al entrar en los cortijos. Los Tenientes Jefes de los Grupos, vigilarán en el plazo de un mes cuando menos una patrulla por cada Puesto o Destacamento a su cargo». ${ }^{13}$

Parece lógico pensar que si uno de los mandos responsables de la contrainsurgencia franquista tenía que insistir en que los jefes vigilasen a la tropa era porque esta no se mostraba todo lo profesional y eficaz que debería en el empeño de sus funciones. De hecho, se deduce una falta de confianza en lo que respecta a los guardias civiles que debían moverse y actuar en el teatro de operaciones, pues de lo contrario difícilmente se habría visto movido a ordenar a los oficiales y suboficiales que controlasen de cerca a la tropa, o que incluso la siguiesen para cerciorarse de que la guerra se estaba llevando a cabo con la beligerancia esperada.

Si algo destacó en la carrera militar de Limia Pérez fueron los buenos resultados que le otorgaron estrategias como la penetración de las redes de guerrilleros y enlaces para lograr infiltraciones, colaboraciones y delaciones. Precisamente, a finales de los años cuarenta y principios de los cincuenta se mostró muy preocupado por la falta de profesionalidad y celo de algunos oficiales en relación con las estrategias de información y acercamiento a los resistentes. En este sentido, las contrapartidas fueron el mejor instrumento de la Guardia Civil para lograr atraer a elementos civiles, pues lograban su colaboración a través de diferentes medios como las recompensas económicas, los ingresos en el cuerpo o también a través de las coacciones. Sin embargo, muchos guardias se saltaron las normas o las praxis que Limia se había encargado de escribir y distribuir entre la tropa. Así pues, al conocer las malas prácticas de algunos miembros de la Benemérita granadina prohibió que ningún

13. AHPCE. Documentos Guardia Civil. 136. Comandancia de Granada. Órdenes/ Instrucciones. Caja 106. Carpeta 1/1. Orden especial sobre servicio de contrapartidas. 
jefe, oficial, suboficial o clase estuviese en contacto directo con aquellos enlaces o confidentes que colaboraban con las contrapartidas. Limia se vio obligado a dar estas instrucciones tras haber comprobado in situ que muchos guardias que no formaban parte de estas unidades especiales se entrevistaban con los colaboradores. ${ }^{14}$

Ahora bien, parece que la imagen de solvencia que pretendía dar en su documentación no siempre mostró la realidad de sus métodos. De esto dio buena cuenta el general de la Guardia Civil Manuel Prieto López. Este compañero de armas se quejó sin vacilaciones sobre el proceder de Limia Pérez cuando se encargaron de luchar conjuntamente: «¡Pero que puñetas! A mí me mató Limia un confidente, que si yo hubiese podido, hubiese matado a Limia!». El general Prieto señaló sobre Limia que este era un hombre bien visto por sus superiores porque «iba a lo práctico». El régimen quería acabar con los guerrilleros y Prieto se preguntaba: «¿Cómo se puede acabar? Se busca al que es práctico. Esta clase llega y se dicen: «A mí que me tengan miedo porque el primer día que llegue establezco estas premisas: al primero que me levante la voz, lo mato»». Resulta evidente que la relación entre ambos no fue buena. De hecho, el general Prieto no se mordió la lengua y explicó los motivos que le hicieron entrar en conflicto con su compañero: «no me gustó cómo llegó en plan de enterado, quizás porque sabía que yo soy muy presumido. Lo que hacía Limia también sabía hacerlo yo y no necesitaba que me diera lecciones nadie». Tan celoso era en sus métodos el citado general que en una ocasión se calló ante Limia el trabajo que llevaba tiempo realizando con un enlace. Aquel silencio acabaría saliendo caro, para él y sobre todo para su enlace, ya que por orden de Limia el individuo fue ejecutado por una contrapartida al negarse a colaborar en un servicio que no había sido organizado ni informado por su contacto con el cuerpo, el general Prieto (Romero Navas, 1997, pp. 24-25).

De esta experiencia se colige una de las características de la guerra irregular que no ha quedado convenientemente reflejada en las fuentes, como son las tensiones generadas a raíz de las malas relaciones personales entre compañeros del Instituto. De las palabras de Prieto se desprende que el carácter vanidoso de ambos mandos hizo que mantuviesen una relación tirante, más allá de las diferencias con respecto a las prácticas contrainsurgentes que debían seguirse para alcanzar la victoria. Sin embargo, ante todo, el testimonio del general muestra cómo las directrices y su puesta en práctica no siempre fueron de la mano, como prueba la muerte del mencionado enlace, que tiró por tierra las

14. AHPCE. Documentos Guardia Civil. 136. Comandancia de Granada. Órdenes/ Instrucciones. Caja 106. Carpeta 1/1. Orden especial sobre servicio de contrapartidas. 
órdenes de Limia sobre el tratamiento de los colaboradores según hemos visto más arriba.

Entre 1947 y 1948 el teniente coronel volvió a dar muestras de enfado y disgusto con la tropa durante su paso por Ciudad Real. Molesto por la intromisión de algunos guardias en labores que debían ser exclusivas de las contrapartidas o de los grupos móviles terminó por encolerizarse ante la forma de actuar de algunos comandantes de puestos y destacamentos en relación con los interrogatorios. De esta forma, en abril de 1948 advirtió que tenía sospechas de que algunos jefes llamaban a los colaboradores al cuartel, por lo que los exponían a que la guerrilla pudiese identificarlos y se vengasen por ello. Limia creía que aquel tipo de actuaciones estaban entorpeciendo el operativo contrainsurgente, porque «en ocasiones malogran las gestiones y servicios de información». Con el fin de evitarlo mandó que para cualquier posible contacto con un confidente primero se avisase al oficial jefe de los grupos móviles o a él mismo. Para que su directriz se cumpliese no dudó en amenazar a sus subordinados: «caso de contravenir la presente orden y malograrse algún servicio, exigiré la más estrecha responsabilidad a los culpables». ${ }^{15}$

Pocos meses después, en noviembre de 1948 Limia volvió a mostrarse tremendamente decepcionado con los resultados de la contrainsurgencia en Ciudad Real. En esta ocasión no cargó contra quienes tiraban por tierra el trabajo con los confidentes, sino contra los guardias encargados de los servicios de observación y emboscada en chozos y casas de campo. El gran valor de la fuente me lleva a copiarla parcialmente a pesar de su extensión:

«Habiendo observado que a pesar del intenso servicio que tengo ordenado de observación y emboscadas [...] son frecuentisimos [sic] los atracos cometidos por los bandoleros en aquellos lugares precisamente en las horas en que deben estar montados los servicios de emboscada, sin que en ningun [sic] caso se haya producido ningun [sic] encuentro, he sacado el convencimiento de que tales servicios no se ejecutan con la extensión de horas y sigilo que es necesario para la sorpresa, habiendo comprobado esta sospecha en varias ocasiones en que han sido corregidos los ejecutantes del servicio. Tengo asi [sic] mismo sospechas de que los Grupos se retiran a descansar a los caserios [sic] poco despues [sic] de anochecido en lugar de hacerlo lo más pronto a las 23 horas como está ordenado, después de efectuado el apostadero. Por tales circunstancias prevengo a todos el más exacto cumplimiento de mis órdenes y la constante vigilancia de los mandos para asegurarse de ello [...] pues estoy dispuesto caso de comprobarse negligencia o incumplimiento a solicitar la expulsión del Cuerpo de los responsables, de haber sido atracado algun [sic]

15. AHPCE. Caja 105, carpeta 3/1. Servicio de Información de la Guardia Civil. Órdenes. Orden n. ${ }^{\circ} 20$. 
chozo o caserío sobre el que tuvieran nombrado vigilancia. [...] Espero de todos el mayor espíritu y entusiasmo para acabar en breve plazo con lo poco que queda de bandolerismo en esta provincia, siendo lamentable tener que poner de ejemplo a los propios bandoleros que con desprecio de la fatiga e inclemencias del tiempo viven y pernoctan en el monte, haciendo marchas nocturnas de largo recorrido que prueban su voluntad y recia energía y que es preciso contrarrestar dando por nuestra parte pruebas de superioridad en todos los órdenes, resistiendo con mayor ahinco [sic] las fatigas y penalidades del servicio y ejecutandolo [sic] con el mayor celo, exactitud y entusiasmo». ${ }^{16}$

Esta orden es sin duda uno de los mejores documentos que se han conservado sobre la lucha antiguerrillera en España. Sobre todo, nos muestra las tremendas dificultades de la guerra irregular, incluso para el bando que a priori goza de mayor fortaleza y capacidad bélica. La reprimenda que lanza contra los guardias es tremenda llegando incluso a acusarles de falta de profesionalidad al considerar que no están acatando sus órdenes. Aparecen palabras de admiración hacia las cualidades combativas de los guerrilleros, a los que sitúa como referente a imitar dada la enorme capacidad de resistencia y sacrifico de la que estaban dando muestra desde hacía años. Así pues, Limia no daba crédito al ver que a pesar de toda la superioridad de la que gozaba la Guardia Civil los guerrilleros eran capaces de contrarrestar la represión y los operativos, de ahí que responsabilizara a las tropas y sus mandos de los constantes fracasos en la lucha contra las partidas.

Además, la sempiterna amenaza de la expulsión volvía a pesar una vez más sobre los guardias civiles, una cuestión que no puede ser obviada teniendo en cuenta la situación de pobreza dominante en los años cuarenta y cincuenta, donde buena parte de la tropa procedía de las clases populares y donde miles de familias dependían de estos sueldos para su propia supervivencia. De esta forma, el miedo a quedarse en la calle no solo causaba un gran efecto entre la tropa y la oficialidad, sino que además estaba bien justificado, ya que solo entre 1950 y 1954 fueron expulsados del cuerpo 2.944 hombres. Un contexto de tensión constante que quedó perfectamente reflejado en las palabras del general Díez-Quijada, quien subrayaba que: «la expulsión significaba regresar a una situación de parado, de ahí, yo creo que los guardias tenían tanto miedo a sus jefes como a los maquis» (López Corral, 2011, p. 418).

A su llegada a la Comandancia de Ciudad Real en agosto de 1947 ordenó entre otras cosas la prohibición de trasladar los cadáveres de los guerrilleros sin su autorización. Si bien el teniente coronel no especificó en sus instrucciones

16. AHPCE. Caja 105, carpeta 3/1. Servicio de Información de la Guardia Civil. Órdenes. Orden n. ${ }^{\circ} 27$. 
las razones que le llevaban a tomar aquella decisión resulta probable que esta directiva tuviera como fin impedir la exposición de los cadáveres ante la población. A diferencia de lo que ocurría en otras provincias en las que era costumbre mostrar los cadáveres de los guerrilleros en plazas y cementerios para escarmentar y atemorizar a los vecinos, parece ser que Limia se mostró contrario a ello. Además, vetó tanto el registro de las ropas como la incautación de cualquier objeto que pudiesen encontrar entre las pertenencias de los guerrilleros, una segunda medida que buscó poner fin a un problema que debió ser habitual: la apropiación de los efectos personales del enemigo por parte de los guardias, dado su valor potencial dentro de la estrategia basada en la obtención de información. Finalmente, ordenó el cese de las torturas sobre los detenidos, añadiendo que en caso de hallarse guerrilleros heridos o a punto de fallecer tenían que ser interrogados y preguntados sobre «ranchos, estafetas, enlaces y puntos de apoyo, gentes que formaban su partida y armas que llevan, los efectos recogidos, armas propaganda [sic] etc.».

Ahora bien, un año después, concretamente en julio de 1948, Limia tuvo que recordar a sus subordinados la obligación de cumplir su orden anterior. Parece ser que los guardias no siguieron sus instrucciones tal y como él esperaba, y por eso volvió a recurrir a la amenaza de la expulsión:

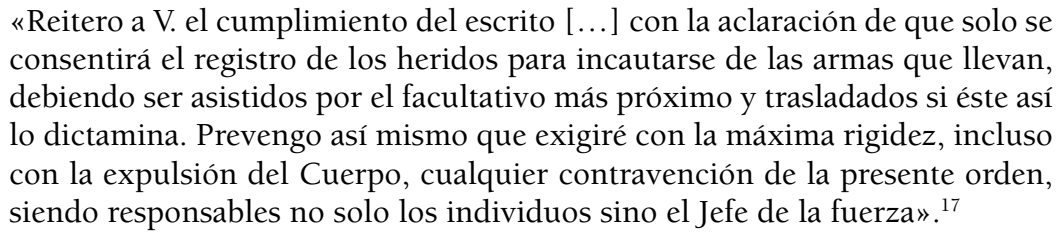

Las labores de información fueron otro aspecto que causó tensiones y disputas entre guardias, algo que también ha pasado desapercibido hasta la fecha y que se encuentra muy presente en la documentación de Limia. Como jefe de la Comandancia de Ciudad Real recordó a los oficiales y guardias que:

«De todos los atracos, actos de bandolerismo y cualquier suceso de importancia, los Comandante [sic] de Puesto o Destacamentos, darán cuenta por el medio más rápido a esta Jefatura (teléfono, telegrafo [sic] o radio) y caso de carecer de medios, lo haran [sic] a su inmediato superior quien se encargará de hacerlo a esta Jefatura, por los medios citados». ${ }^{18}$

17. AHPCE. Caja 105, carpeta 3/1. Servicio de Información de la Guardia Civil. Órdenes. Orden n. ${ }^{\circ} 5$.

18. AHPCE. Caja 105, carpeta 3/1. Servicio de Información de la Guardia Civil. Órdenes. Orden $n .^{\circ} 7$. 
Desde 1945 el Estado Mayor de la Guardia Civil había dado diversas instrucciones para recordar a los Jefes de Tercio, Comandancia, Línea y Puesto la obligación que tenían de dar cuenta de toda información que tuviese vinculación con la eliminación de la guerrilla. ${ }^{19}$ Sin embargo, por más que se insistió en ello, estas órdenes no se siguieron con la seriedad exigida por la Dirección, una visión compartida por Eulogio Limia Pérez. El Estado Mayor y numerosos mandos contrainsurgentes fueron muy conscientes de que para combatir mejor a las partidas se necesitaba que quienes estuviesen en el teatro de operaciones transmitiesen de forma rápida y solvente cualquier información. Lo aprendido en el sur se puede aplicar en el levante o en el norte, y con ello se podía aumentar la eficiencia de la estrategia contrainsurgente.

\section{Las limitaciones de la guerra contrainsurgente y la adaptabilidad de los guerrilleros}

Siguiendo el rastro de Limia por Ciudad Real encontramos una serie de disposiciones que muestran tanto sus dotes de mando como la dificultad de la guerra irregular. En el teatro de operaciones los guerrilleros aprendían a convivir con los cambios de estrategia adoptados por los guardias civiles.

Sin ir más lejos, en el ocaso del verano de 1947 Limia emitió una orden para mejorar algunos servicios, ya que los éxitos iniciales de estas prácticas se vieron reducidos por la adaptación de los resistentes armados. Por ejemplo, había comprobado que los guerrilleros se apostaban durante el día y realizaban desplazamientos cortos durante las noches. El objetivo de aquellos movimientos era poder entrevistarse con sus enlaces, por lo que Limia entendió que era necesario «adoptar [...] una modalidad delmservicio [sic] que contrareste [sic] aquellos propósitos y de por resultados el descubrimiento, eliminación o captura de los foragidos [sic]». A consecuencia de ello estableció que para el servicio de «observación diurna y pernocte en pueblos y caseríos» todos los Puestos y Destacamentos nombrarían en días alternos una patrulla de tres a cuatro hombres que debían apostarse media hora antes del amanecer en un punto dominante del terreno. Limia ordenó que el servicio debía practicarse con el «máximo sigilo», y en cada turno podía apostarse un vigía mientras el resto de la tropa descansaba. El oficial hizo especial hincapié en que no debía darse ningún tipo de información sobre el servicio a nadie, por lo que los

19. AHPSev. GC1, Registro 35, fichero 299; GC1, Registro 30, fichero 119 y GC1, Registro 31 , fichero $34 \mathrm{r}$. 
guardias debían mostrarse cautos ante los «moradores de los caseríos y otras personas». ${ }^{20}$

Sin embargo, cuando hacía un año que Limia había ordenado esos procedimientos para los servicios de «observación diurna y pernocte en pueblos y caseríos» se vio obligado a cambiar sus instrucciones en abril de 1948. El teniente coronel señalaba que había vuelto a comprobar cómo «los bandoleros han rectificado su táctica en la forma, hora y lugares de cometer los atracos, tratando de contrarrestar los efectos del servicio establecido en la actualidad», por lo que los guardias debían responder con una «nueva táctica con otras normas conducentes a malograr sus actuaciones y conseguir su persecución y captura». Así pues, anuló su escrito del año anterior y dispuso que los Puestos y Destacamentos debían asignar diariamente (y subrayaba en su escrito la palabra) una patrulla de tres o más guardias que, tras haber comido a las 12 o 13 horas, debían salir de inmediato para realizar servicios de observación, mientras que en verano debían esperar un par de horas después de haber comido. Los guardias debían colocarse convenientemente en puntos desde donde pudiesen dominar caseríos, chozos y majadas, permaneciendo allí hasta que llegase la noche. Una vez que la luz natural les impidiese ver con claridad debían organizar con sigilo un servicio de emboscadas en las proximidades de caseríos, chozos y majadas donde pudieran ocultarse las partidas. Además, Limia ordenó que los reconocimientos no se realizasen por toda la sierra, sino en aquellos lugares donde fuese fácil ocultarse por existir matorral, de manera que tal y como suele ser habitual en la guerra irregular el medio físico devenía un elemento de vital importancia.

No obstante, por más que el teniente coronel reformulaba los servicios de los grupos móviles los éxitos esperados por el mando no llegaban. A la orden dictada en 1947 le siguió la de 1948, en la que se replanteaba cómo debían actuar los guardias ante la capacidad de aprendizaje de la que daban muestra los guerrilleros. Sin embargo, a la altura de 1949 la cuestión ya no era que los resistentes armados conociesen las estrategias contrainsurgentes de la dictadura, sino que para Limia el problema se encontraba en el seno de la Benemérita. En su tercera orden de enero de 1949, sobre los servicios de observación y emboscada, señalaba que había comprobado cómo sus directrices no habían dado el resultado esperado, y lo achacaba a la tropa, que según él no se estaba ciñendo al contenido de sus instrucciones. ${ }^{21}$

20. AHPCE. Caja 105, carpeta 3/1. Servicio de Información de la Guardia Civil. Órdenes. Orden $n .^{\circ} 11$.

21. AHPCE. Caja 105, carpeta 3/1. Servicio de Información de la Guardia Civil. Órdenes. Orden n. ${ }^{\circ} 31$. 
Ahora bien, analizada esa nueva orden resulta que los cambios estratégicos eran nulos en relación con las dos anteriores. Por el tono que utiliza parece ser que en aquella ocasión lo que realmente pretendía era recordar el objetivo que tenían los grupos móviles, a la par que mostrar su enfado de forma abierta hacia los guardias. Con aquella orden de enero trató de dar una nueva oportunidad a sus subordinados, pero estos parece ser que no la aprovecharon, ya que en abril de 1949 directamente mandó disolver los grupos móviles:

«Habiendo podido comprobar que en la mayoria [sic] de los casos los servicios de observación y emboscada encomendados a la fuerza de la zona de bandolerismo no dán [sic] el rendimiento apetecido en gran parte por falta de celo y espíritu de sacrificio en la tropa que los ejecuta, siendo en la mayoria [sic] de los casos vista por los bandoleros que inmediatamente después cometen impunemente los atracos, a veces a distancias muy pequeñas del lugar del observatorio o apostadero, he tenido por conveniente variar mi orden [...] previniendo por última vez a todos que estoy dispuesto a aplicar las máximas sanciones a los que no cumplimenten los servicios tal y como se ordena, llegando segun [sic] los casos incluso a solicitar la expulsión inmediata del Cuerpo». ${ }^{22}$

Si los resultados no llegaban volvía a aparecer otra vez la sombra del castigo por medio de la expulsión. Además, en esta ocasión aparece una cuestión muy relevante, como es la del miedo de los guardias civiles a entablar combate con los guerrilleros.

Así pues, esa nueva orden vuelve a ser sumamente valiosa para entender las dificultades de la guerra irregular, por mucho que en 1949 la guerrilla manchega se encontraba en fase de liquidación. Sin embargo, aunque Francisco Moreno señalaba que con la muerte de los tres últimos guerrilleros de la célebre partida de «Manco de Agudo» en marzo de 1949 se puso fin a la guerrilla en la región (Moreno, 2001, p. 168), lo cierto es que la documentación nos dice otra cosa. La Guardia Civil no había dado por finalizada la guerra, puesto que el enfado de Limia y la supresión del servicio de observación se produjo un mes más tarde del mencionado acontecimiento.

Ahora bien, si el mando del Instituto consideraba que los grupos móviles no hicieron del todo bien su trabajo las contrapartidas tampoco fueron una excepción. De hecho, en la orden de abril de 1949 les encargó a estas las tareas de los grupos móviles, porque un año antes, en marzo de 1948, había ordenado la disolución de las contrapartidas ante la nula efectividad de estas sobre el teatro de operaciones:

22. AHPCE. Caja 105, carpeta 3/1. Servicio de Información de la Guardia Civil. Órdenes. Orden n. ${ }^{\circ} 33$. 
«Habiendo observado que la mayor parte de los actuales Jefes de Contrapartidas, carecen del espíritu, entusiasmo, y sacrificio que son necesarios para el difícil cumplimiento de la misión que se les había confiado [...] he creido [sic] conveniente para terminar con este estado de cosas, cambiar radicalmente la organización de las fuerzas con arreglo a las siguientes normas». ${ }^{23}$

Uno de los máximos responsables de la lucha antiguerrillera venía a señalar que los guardias civiles disfrazados de partisanos eran reconocidos habitualmente por la población civil y los guerrilleros, por lo que no lograban dar captura ni establecer contacto con ninguna partida. Por ello eliminó todas las contrapartidas y no solamente algunas. Así pues, este documento nos pone ante la necesidad de reinterpretar el carácter decisivo de esta estrategia contrainsurgente, cuya eficacia ha tendido a ser sobredimensionada por la historiografía.

\section{Conclusión}

A través de las órdenes e interpretaciones de Limia hemos comprobado el mando férreo e intransigente que ejerció sobre sus subalternos. En este sentido, hablamos de una realidad fundamental de aquel conflicto armado que muchas veces ha quedado oculta, pero que contribuyó a darle forma. Es posible que entre otras cosas acabara empujando a la propia tropa a emplearse de forma más expeditiva y radical en el cumplimiento de lo que se esperaba de ella, al entender que de ello dependía su propio éxito y su supervivencia. Una realidad que muchas veces ha conformado la cara oculta de aquella guerra, pero que fue el día a día de la tropa, tal y como lo demuestra la experiencia del guardia José Antonio Camposo de Haro:

«Cada cierto tiempo recibíamos la visita-siempre sin previo aviso- de nuestros superiores, que venían a la Casa Cuartel para una inspección general. Me acuerdo que todos temíamos especialmente las visitas del Teniente Limia, porque era un mando estricto y autoritario como ningún otro; no sólo revisaba cuartel, armamento y uniformes, sino que también entraba en nuestras casas para comprobar si estaban limpias y ordenadas... jnada escapaba a su control! Los guardias no podíamos hablarle directamente, sólo el Cabo se dirigía a él; creo que todos le teníamos miedo» (Oyonarte, 2016).

El análisis de la contrainsurgencia sublevada y franquista se ha visto relegado a un segundo plano por parte de la historiografía. En líneas generales, los grandes estudios sobre la resistencia antifranquista han incluido epígrafes sobre la lucha antiguerrillera, pero estos han tendido a repetir lo consabido y a ofrecer una

23. AHPCE. Caja 105, carpeta 3/1. Servicio de Información de la Guardia Civil. Órdenes. Orden n. ${ }^{\circ} 27$. 
imagen de solvencia y éxito que tal y como hemos visto no se corresponde con la realidad.

El objetivo de este artículo ha sido tomar como referencia una serie de estudios académicos y parte de la documentación generada por las fuerzas del orden franquistas para complementar la visión de aquella guerra irregular activa durante casi dos décadas. A través de la relectura de los «papeles de Limia» y de otras fuentes documentales, junto a la bibliografía especializada, comprobamos cómo los éxitos de la Guardia Civil en la lucha antiguerrillera solo fueron posible después de fracasos que obligaron a modificar continuamente las instrucciones. Al calor de todo ello también hicieron acto de presencia las tensiones y disputas internas entre miembros del cuerpo, junto al miedo de la tropa a verse expulsados y, por tanto, a perder el sustento económico de sus familias.

\section{Archivos}

Archivo del Partido Comunista de España

Archivo Histórico Provincial de Castellón

Archivo Histórico Provincial de Málaga

Archivo Histórico Provincial de Sevilla

Archivo General de la Administración

Archivo General Militar de Ávila

\section{Bibliografía}

ABAD GAllEGO, Xoán Carlos (2004). El Gobernador Manuel Gómez Cantos, un personaje controvertido redentor de «fuxidos» o criminal de uniforme. Glaucopis: Boletín del Instituto de Estudios Vigueses, 10, 131-174.

BLANCO ESCOLÁ, Carlos (2000). La incompetencia militar de Franco. Madrid: Alianza Editorial.

CHAMORRO RODRÍGUEZ, Carlos Alfonso (2019). Destacamento de La Sía: el control de la guerrilla. En CHAMORRO RODRÍGUEZ, Carlos Alfonso et al. La Guardia Civil. 175 años en Burgos (193-200). Burgos: Diputación de Burgos.

CHAVES PALACIOS, Julián (2001). Fuerzas del orden público y oposición al régimen de Franco en los cuarenta. Críticas de la Policía Armada a la Guardia Civil. En MORALES MOYA, Antonio (coord.), Las claves de la España del siglo XX. El Estado y los ciudadanos (221-233). Madrid: Sociedad Estatal España Nuevo Milenio.

DÍAZ DÍAZ, Benito (2004). La actividad guerrillera en Toledo: la 1. ${ }^{a}$ Agrupación. En DÍAZ DÍAZ, Benito (coord.), La guerrilla en Castilla-La Mancha. Ciudad Real: ALMUD. 
FUENTES GONZÁLEZ, Antonio Daniel (2015). Gente de la sierra, maquis, guerrilleros, bandoleros... Sociolingüística gentilicia para el tiempo abatido», Tonos digital: Revista de estudios filológicos, 28.

GARCÍA CARRERO, Francisco Javier (2013). Pereita Vela, Gómez Cantos y Navarrete Alcal, tres mandos de la Guardia Civil hermanados en la represión y en el deshonor en Badajoz durante la guerra civil y el primer franquismo. En CHAVES PALACIOS, Julián (dir.), El itinerario de la memoria. Derecho, historia y justicia en la recuperación de la memoria histórica en España, Vol. II (101-120). Madrid: Sequitur.

GARCÍA CARRERO, Francisco Javier (2013). Manuel Gómez Cantos. Historia y memoria de un mando de la Guardia Civil. Córdoba: Servicio de Publicaciones de la Universidad de Córdoba.

GARCÍA CARRERO, Francisco Javier (2014). El cuerpo de la Guardia Civil y el guardia civil Manuel Gómez Cantos: nuevas aportaciones de un mando polémico. Boletín de la Real Academia de Extremadura de las Letras y las Artes, 22, 183-218.

GARCÍA CARRERO, Francisco Javier (2016). Navarrete Alcal, el guardia civil que «liberó» Fuente de Cantos del «yugo marxista». En LORENZANA DE LA PUENTE, Felipe (coord.), XVII Jornada de Historia de Fuente de Cantos (293-303). Badajoz: Sociedad Extremeña de Historia.

GONZÁLEZ DEVÍS, Raül (2016). Tràgedies silenciades. Repressió franquista i maquis a les comarques del nord del País Valencià. Castellón de la Plana: Publicacions de la Universitat Jaume I. https://doi.org/10.6035/HistoriaMemoria.2017.4.2ed GONZÁLEZ DEVÍS, Raül (2018). Maquis i masovers. Entre la resistència, la supervivència i el terror. Benicarló: Onada Edicions.

LÓPEZ CORRAL, Miguel (2011). Guardia Civil. Claves históricas para entender a la Benemérita y a sus hombres (1844-1975). Madrid: La Esfera de los Libros.

MARCO, Jorge (2006). Los documentos de Eulogio Limia Pérez y la guerrilla. Hispania Nova Revista de Historia Contemporánea, 6.

MARCO, Jorge (2011). Ecos partisanos. La memoria de la resistencia como memoria conflictiva. Historia del presente, 17, 79-91.

MARCO, Jorge (2012). Guerrilleros y vecinos en armas: identidades y culturas de la resistencia antifranquista. Granada: Editorial Comares.

MARCO, Jorge (2013). Una Corea en pequeño. Contrainsurgencia y represión de la guerrilla en España, 1939-1952. Contenciosa, 1, 1-21.

MORENO GÓMEZ, Francisco (2001). La resistencia armada contra Franco. Tragedia del maquis y la guerrilla. Barcelona: Editorial Crítica.

ROMERO NAVAS, José Aurelio (1997). Recuperando la memoria. Entrevistas a personas que por circunstancias, vivieron en los años cuarenta, una etapa difícil en sus vidas: guerrilleros, guardias civiles y campesinos. Málaga: Centro de Ediciones de la Diputación de Málaga. 
SÁNCHEZ CERVELLÓ, Josep (2006). Maquis: el puño que golpeó al franquismo. La Agrupación Guerrillera de Levante y Aragón (AGLA). Barcelona: Flor del Viento Ediciones.

V. OYONARTE, Mariló (20 de agosto de 2016). «El Honor Es Mi Divisa»: Recuerdos de un guardia civil (I parte). Recuperado de https://www.alhama.com/digital/ myblog/caminos-gentes/9413-el-honor-es-mi-divisa-recuerdos-de-un-guardiacivil-i-parte

YUSTA, Mercedes (2003). Guerrilla y resistencia campesina. La resistencia armada contra el franquismo en Aragón (1939-1952), Zaragoza: Prensas Universitarias de Zaragoza.

YUSTA, Mercedes (2005). La guerra de los vencidos. El maquis en el Maestrazgo turolense, 1940-1950. Zaragoza: Institución Fernando el Católico. 